\title{
Tubing Length for Long-Term Oxygen Therapy
}

\author{
Carolina Aguiar PT MSc, Josy Davidson PT PhD, Andréa K Carvalho PT PhD, \\ Vinícius C Iamonti PT MSc, Felipe Cortopassi PT, \\ Oliver A Nascimento MD, and José R Jardim MD
}

\begin{abstract}
BACKGROUND: Most patients on long-term oxygen therapy use stationary oxygen delivery systems. It is not uncommon for guidelines to instruct patients to use tubing lengths no longer than $19.68 \mathrm{ft}(6 \mathrm{~m})$ when using an oxygen concentrator and $49.21 \mathrm{ft}(15 \mathrm{~m})$ when using cylinders. However, these concepts are not based on sufficient evidence. Thus, our objective was to evaluate whether a 98.42-ft (30-m) tubing length affects oxygen flow and $\mathrm{F}_{\mathrm{IO}_{2}}$ delivery from 1 cylinder and 2 oxygen concentrators. METHODS: The 3 oxygen delivery systems were randomly selected, and 1,3 , and $5 \mathrm{~L} / \mathrm{min}$ flows and $\mathrm{F}_{\mathrm{IO}}$, were measured 5 times at each flow at the proximal and distal outlets of the tubing by a gas-flow analyzer. Paired Student $t$ test was used to analyze the difference between flows and $\mathrm{F}_{\mathrm{IO}_{2}}$ at proximal and distal outlets of tubing length. RESULTS: A total of 45 flows were measured between proximal and distal outlets of the 98.42-ft (30-m) tubing. Flows were similar for 1 and $3 \mathrm{~L} / \mathrm{min}$, but distal flow was higher than proximal flow at $5 \mathrm{~L} / \mathrm{min}(5.57 \times 5.14$ $\mathrm{L} / \mathrm{min}, P<.001) . \mathrm{F}_{\mathrm{IO}_{2}}$ was lower at distal than proximal outlet tubing at flows 1,3 , and $5 \mathrm{~L} / \mathrm{min}$, but the mean difference between measurements was less than $1 \%$. CONCLUSIONS: Tubing length of $98.42 \mathrm{ft}(30 \mathrm{~m})$ may be used by patients for home delivery oxygen with flows up to $5 \mathrm{~L} / \mathrm{min}$, as there were no important changes in flows or $\mathbf{F}_{\mathrm{IO}_{2}}$. Key words: oxygen inhalation therapy; laboratory test; instrumentation. [Respir Care 2015;60(2):179-182. (c) 2015 Daedalus Enterprises]
\end{abstract}

\section{Introduction}

Long-term oxygen therapy (LTOT) plays an important role in management of hypoxemic patients ${ }^{1,2}$ due to its benefits related to lung function, ${ }^{3}$ survival, ${ }^{4}$ pulmonary hypertension, and exercise. ${ }^{5}$ However, the effect of LTOT on quality of life remains controversial. ${ }^{6}$ Some studies have shown a reduced quality of life in patients under LTOT ${ }^{5,6}$ due to the excessive noise produced by the oxygen concentrators (OCs) and/or limitation of patient's mobility. ${ }^{7-9}$

\footnotetext{
The authors are affiliated with the Respiratory Division, Departament of Medicine, Escola Paulista de Medicina, Federal University of São Paulo, São Paulo, Brazil.

The authors have disclosed no conflicts of interest.

Correspondence: Josy Davidson PT PhD, Rua Botucatu, 740, $3^{\circ}$ andar, Pneumologia (Respiratory Division), Departament of Medicine, Escola Paulista de Medicina, Federal University of São Paulo, São Paulo 04039002, Brazil. E-mail: josydavidson@yahoo.com.br.
}

DOI: $10.4187 /$ respcare. 03454
Usually, the majority of patients on LTOT use stationary oxygen delivery systems (ODS) such as cylinders and OCs. It is not uncommon for oxygen providers and guidelines to instruct patients to use tubing lengths no longer than $19.68 \mathrm{ft}(6 \mathrm{~m})$ when using an OC and $49.21 \mathrm{ft}(15 \mathrm{~m})$ when using cylinders. ${ }^{10}$ This is the usual recommendation for tubing lengths in the literature. ${ }^{8,11}$

Despite the idea that longer tubing would cause reduction in flow and/or $\mathrm{F}_{\mathrm{IO}_{2}}$, we believe that health professionals, oxygen suppliers, and guidelines are establishing their concepts on insufficient evidence. As far as we are aware, only one study investigated the oxygen tubing length and output flows. ${ }^{11}$ The authors showed significant reduction in flow at $2 \mathrm{~L} / \mathrm{min}$ for tubing length greater than $100 \mathrm{ft}$ when using cylinders as an oxygen source and additional flow loss at greater tubing lengths (100-200 ft) with 3-5 L/min from an OC. ${ }^{11}$ However, $\mathrm{F}_{\mathrm{IO}_{2}}$ was not assessed in this study.

Further investigation would provide more evidence for adequate instructions to the patients. Thus, our objective was to evaluate whether $98.42-\mathrm{ft}$ (30-m) tubing affects oxygen flow and $\mathrm{F}_{\mathrm{IO}_{2}}$ delivery from stationary cylinders and OCs. 


\section{TUBING LENGTH FOR LTOT}

\section{Methods}

This was an experimental study conducted at the Pulmonary Rehabilitation Center at Escola Paulista de Medicina, Federal University of São Paulo, São Paulo, Brazil with ODS. Three ODS were randomly selected to assess flows and oxygen concentration: 2 OCs (one by Respironics Millennium [Respironics, Murrysville, Pennsylvania] and the other by Invacare Platinum XL [Invacare, Elyria, Ohio]) and a $6 \mathrm{~m}^{3}$ stationary oxygen cylinder (White Martins, Danbury, Connecticut). One OC of each brand available in our division was randomly chosen; just 1 oxygen cylinder was evaluated, as there was only one brand available in our division at the period of the study.

Flow and $\mathrm{F}_{\mathrm{IO}_{2}}$ were measured at 1,3 , and $5 \mathrm{~L} / \mathrm{min}$ by a gas flow analyzer (VT Plus, Fluke Biomedical, Everett, Washington) previously calibrated at zero flow and at $\mathrm{F}_{\mathrm{IO}_{2}}$ 0.21 connected to the oxygen cylinder or the oxygen concentration (proximal flow and $\mathrm{F}_{\mathrm{IO}_{2}}$ ). Measurement was recorded after a 2-min period once flow stability was reached (Fig. 1A).

Then, a 98.42-ft (30-m) tubing length was connected to the oxygen cylinder or concentrator, and the same gas analyzer was now connected to the distal end of the tubing. In the same way, 2 min elapsed for stabilization of the flow, after which $\mathrm{F}_{\mathrm{IO}_{2}}$ and flow were recorded (distal $\mathrm{F}_{\mathrm{IO}_{2}}$ and flow; see Fig. 1B). Stability of the flows and $\mathrm{F}_{\mathrm{IO}_{2}}$ was defined as when these 2 parameters had reached steadiness for $20 \mathrm{~s}$ at the tubing outlet as read on the gas-flow analyzer graph. Reproducibility was tested at each flow 5 times in a random sequence.

\section{Statistical Analysis}

Measurements of oxygen flows and concentration were expressed as mean and standard deviation. Paired Student $t$ test was used to analyze the difference between flow and $\mathrm{F}_{\mathrm{IO}_{2}}$ at proximal end and at $98.42 \mathrm{ft}(30 \mathrm{~m})$ tubing length (distal flow). The level of significance was set at $P \leq .05$.

\section{Results}

A total of 45 flow measurements were performed: 15 measurements from each ODS. Flows measured were similar between proximal and distal outlets of the $98.42-\mathrm{ft}$ (30-m) tubing at 1 and $3 \mathrm{~L} / \mathrm{m}$; distal flow was higher than proximal flow at $5 \mathrm{~L} / \mathrm{min}(5.57 \times 5.14 \mathrm{~L} / \mathrm{min}, P<.001)$ (Fig. 2). When the ODS flows were individually evaluated, only the $5 \mathrm{~L} / \mathrm{min}$ flow from the cylinder was significantly different, with distal flow higher than proximal flow (Table 1).

A total of $45 \mathrm{~F}_{\mathrm{IO}_{2}}$ measurements were performed: 15 measurements from each ODS. The $\mathrm{F}_{\mathrm{IO}_{2}}$ at 1 and $5 \mathrm{~L} / \mathrm{min}$ flows were significantly lower at the distal than proximal

\section{QUICK LOOK}

\section{Current knowledge}

Long-term oxygen therapy (LTOT) plays an important role in management of hypoxemic patients due to its benefits related to lung function, survival, pulmonary hypertension, and exercise. Quality of life may be reduced in patients under LTOT due to the excessive noise produced by the oxygen concentrators (OCs) and/or limitation of patient's mobility from stationary oxygen systems.

\section{What this paper contributes to our knowledge}

Tubing length of $98.42 \mathrm{ft}(30 \mathrm{~m})$ may be used by patients with home OCs and flows up to $5 \mathrm{~L} / \mathrm{min}$. Despite commonly held beliefs, longer tubing lengths had no clinically important changes in flows or oxygen purity.

outlet tubing (Fig. 3). When the ODS $\mathrm{F}_{\mathrm{IO}_{2}}$ measurements were individually evaluated, the distal $\mathrm{F}_{\mathrm{IO}_{2}}$ was usually lower than the proximal outlet, but with a very small difference that may not have any clinical influence (Table 2).

\section{Discussion}

Inadequate instructions regarding length of oxygen tubing can greatly affect patients in their daily activities, LTOT compliance, and quality of life. A review highlighted factors influencing the compliance of patients using LTOT and emphasized novel strategies and interventions that may prove to be of significant benefit. The authors suggested that the use of a stationary $\mathrm{OC}$ or liquid oxygen with incorporated tubing up to $50 \mathrm{ft}(15.24 \mathrm{~m})$ in length, in conjunction with an additional small M-6 cylinder $(2 \mathrm{~kg}, 4$ $\mathrm{h} / \mathrm{use}$ ) or a small portable liquid reservoir ( $\sim 2 \mathrm{~kg}, 5 \mathrm{~h} / \mathrm{use})$ could be an ideal and complete home oxygen system. ${ }^{12}$ In our study, we observed that long tubing $(30 \mathrm{~m})$ should be safe for patient use, as no important difference was observed between proximal and distal measured flows, except at $5 \mathrm{~L} / \mathrm{min}$. In addition, the difference in $\mathrm{F}_{\mathrm{IO}_{2}}$ between proximal and distal outlets was less than $1 \%$ in all 3 ODS.

Most LTOT system providers and healthcare professionals rely on deficient data when managing oxygen-dependent patients. Moreover, there has been a historical belief that the length of the tubing could affect the oxygen flow in different ODS. Most guidelines still indicate that tubing up to $19.68 \mathrm{ft}(6 \mathrm{~m})$ should be used with OCs and $49.21 \mathrm{ft}(15 \mathrm{~m})$ with cylinders. ${ }^{10}$

Cullen and Koss $^{11}$ recommended tubing lengths up to $200 \mathrm{ft}(60.96 \mathrm{~m})$ for flow up to $3 \mathrm{~L} / \mathrm{min}$ or $100 \mathrm{ft}(30.48 \mathrm{~m})$ for $4-5 \mathrm{~L} / \mathrm{min}$ for Invacare and similar OCs. The authors 

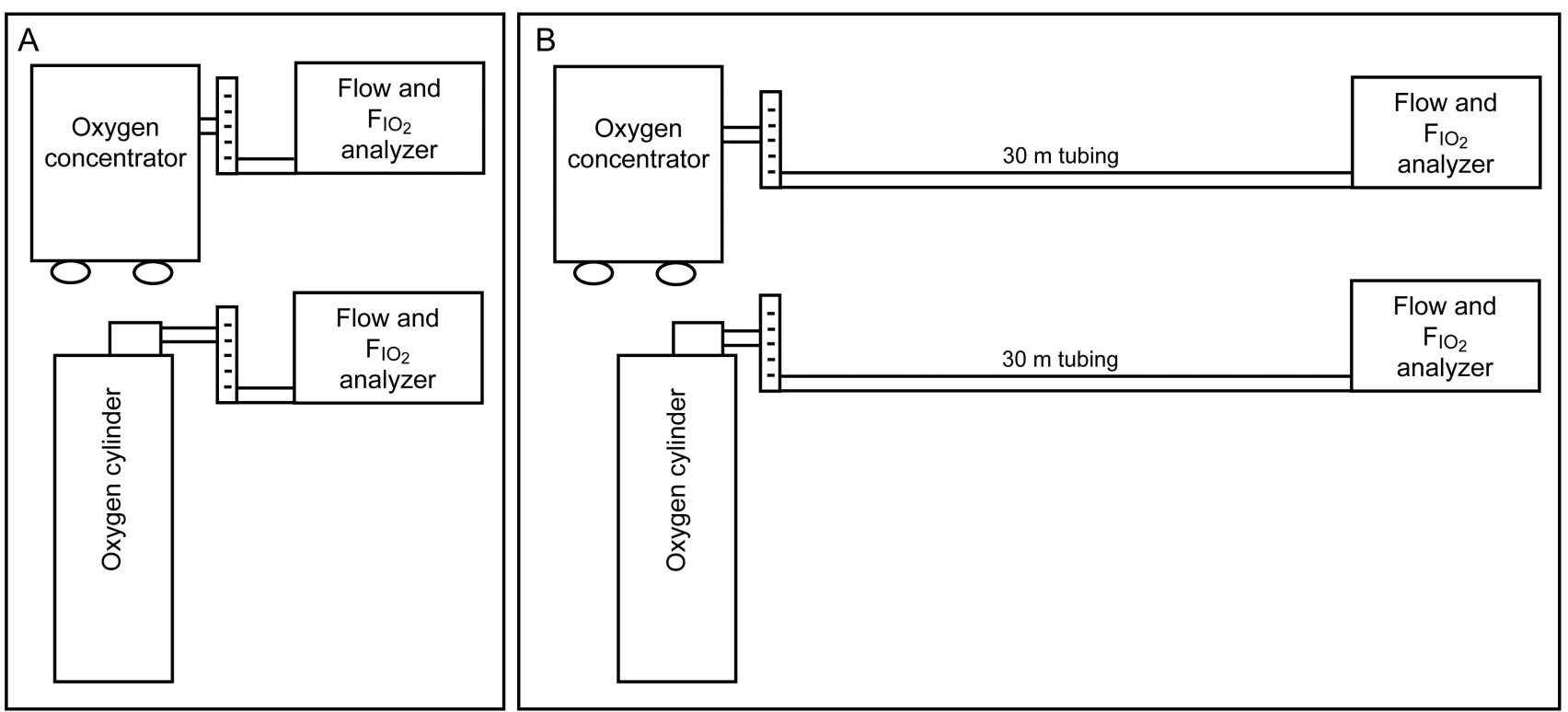

Fig. 1. Scheme of flows and $\mathrm{F}_{\mathrm{IO}_{2}}$ measurements at proximal outlet $(\mathrm{A})$ and distal outlet $(\mathrm{B})$.

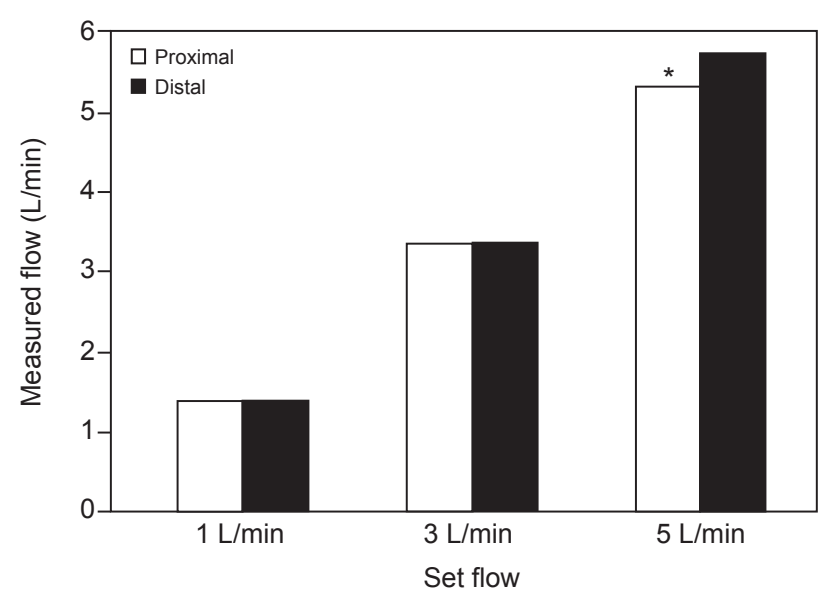

Fig. 2. Mean values of proximal and distal tubing length flows. White bars represent proximal measured flows, and black bars represent distal tubing length measured flows. ${ }^{*} P<.05$.

observed that the cylinder regulator/flow meter system suffered the greatest flow loss, with significant reductions in flow at $2 \mathrm{~L} / \mathrm{min}$ for tubing lengths greater than $100 \mathrm{ft}$ $(30.48 \mathrm{~m})$. The authors attributed the changes in flow to the individual oxygen system operational mechanism.

In the analysis of flow using 3 randomly selected ODS, we observed that there was no change in flow for 1 and 3 $\mathrm{L} / \mathrm{min}$ and only a slight increase for $5 \mathrm{~L} / \mathrm{min}$ flow comparing proximal and 30-m output flows. This is not expected, but there are 2 possible explanations. First, the flow analyzer has some variability (approximately $2 \%$ according to the manufacturer's instructions manual); second, as we have observed previously, ${ }^{12}$ there is a normal flow variation in flow meters. For flow reading at the
Table 1. Flows Values at 1,3, and $5 \mathrm{~L} / \mathrm{min}$ Measured at Proximal and Distal Tubing Length According to 3 Different Devices

\begin{tabular}{lccc}
\hline \hline & $\begin{array}{c}\text { Proximal } \\
\text { Measured } \\
\text { Flow }\end{array}$ & $\begin{array}{c}\text { Distal } \\
\text { Measured } \\
\text { Flow }\end{array}$ & $P$ \\
\hline Oxygen concentrator 1 & & & \\
$1 \mathrm{~L} / \mathrm{min}$ & $1.08 \pm 0.05$ & $1.15 \pm 0.16$ & .24 \\
$3 \mathrm{~L} / \mathrm{min}$ & $3.07 \pm 0.07$ & $3.30 \pm 0.22$ & .55 \\
$5 \mathrm{~L} / \mathrm{min}$ & $5.18 \pm 0.03$ & $5.68 \pm 0.35$ & .36 \\
Oxygen concentrator 2 & & & \\
$1 \mathrm{~L} / \mathrm{min}$ & $1.12 \pm 0.02$ & $1.24 \pm 0,18$ & .66 \\
$3 \mathrm{~L} / \mathrm{min}$ & $3.02 \pm 0.09$ & $3.17 \pm 0.17$ & .21 \\
$5 \mathrm{~L} / \mathrm{min}$ & $5.15 \pm 0.09$ & $5.55 \pm 0.43$ & .02 \\
Cylinder & & & .88 \\
$1 \mathrm{~L} / \mathrm{min}$ & $1.17 \pm 0.02$ & $1.25 \pm 0.16$ & .22 \\
$3 \mathrm{~L} / \mathrm{min}$ & $3.01 \pm 0.09$ & $3.17 \pm 0.26$ & .21 \\
$5 \mathrm{~L} / \mathrm{min}$ & $5.12 \pm 0.05$ & $5.49 \pm 0.43$ &. \\
& & & \\
& &
\end{tabular}

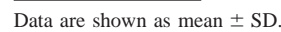

tubing distal end, the flow analyzer had to be disconnected from the proximal end and connected to the distal end and another 2 min elapsed, which may have introduced some flow variation. It is possible that the difference in flow seen may be accounted for by these 2 sources of variation. However, these differences in flow do not seem to have clinical importance, as the mean difference in $\mathrm{F}_{\mathrm{IO}_{2}}$ was less than $1 \%$. Moreover, no difference in flow was seen when the tested flow was $1 \mathrm{~L} / \mathrm{min}$; a small difference of 0.03 $\mathrm{L} / \mathrm{min}$ was seen at $3 \mathrm{~L} / \mathrm{min}$ and approximately $0.4 \mathrm{~L} / \mathrm{min}$ at $5 \mathrm{~L} / \mathrm{min}$. These variations are in keeping with our previous observation of flow meter variation as flow is increased ${ }^{12}$ 


\section{TUBING LENGTH FOR LTOT}

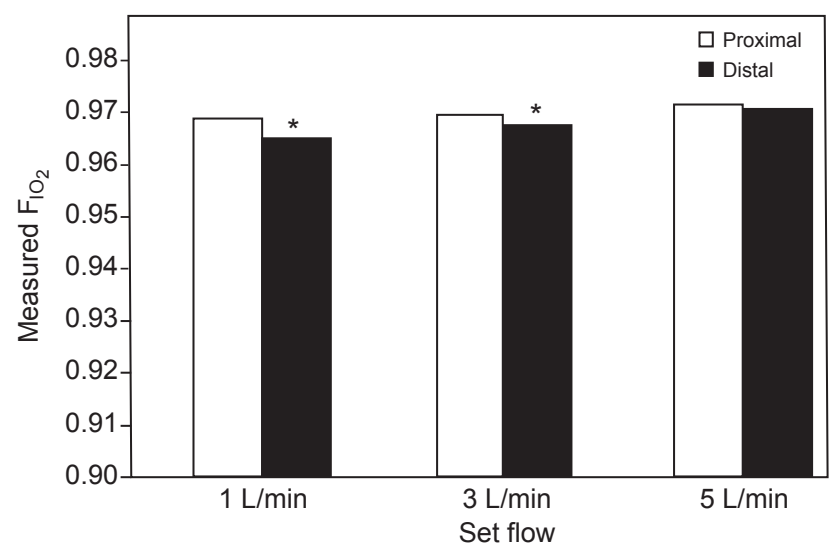

Fig. 3. Mean values of proximal and distal tubing length $\mathrm{F}_{\mathrm{IO}_{2}}$. White bars represent proximal measured $\mathrm{F}_{\mathrm{IO}_{2}}$, and black bars represent distal tubing length measured $\mathrm{F}_{\mathrm{IO}_{2} .}{ }^{{ }^{*}} P<.05$.

Table 2. $\quad \mathrm{F}_{\mathrm{IO}_{2}}$ Values at 1, 3, and $5 \mathrm{~L} /$ min Measured at Proximal and Distal Tubing Length Flow According to 3 Different Devices

\begin{tabular}{cccc}
\hline \hline & $\begin{array}{c}\text { Proximal } \\
\text { Measured } \mathrm{F}_{\mathrm{IO}_{2}}\end{array}$ & $\begin{array}{c}\text { Distal } \\
\text { Measured } \mathrm{F}_{\mathrm{IO}_{2}}\end{array}$ & $\begin{array}{c}\text { \% Difference } \\
\text { Between } \mathrm{F}_{\mathrm{IO}_{2}}\end{array}$ \\
\hline Oxygen concentrator 1 & & & \\
$1 \mathrm{~L} / \mathrm{min}$ & $94.08 \pm 0.04$ & $93.86 \pm 0.05^{*}$ & 0.22 \\
$3 \mathrm{~L} / \mathrm{min}$ & $94.76 \pm 0.09$ & $94.72 \pm 0.04$ & 0.04 \\
$5 \mathrm{~L} / \mathrm{min}$ & $94.94 \pm 0.05$ & $95.32 \pm 0.04^{*}$ & -0.38 \\
Oxygen concentrator 2 & & & \\
$1 \mathrm{~L} / \mathrm{min}$ & $94.32 \pm 0.24$ & $93.48 \pm 0.31^{*}$ & 0.84 \\
$3 \mathrm{~L} / \mathrm{min}$ & $95.28 \pm 0.18$ & $95.26 \pm 0.09$ & 0.02 \\
$5 \mathrm{~L} / \mathrm{min}$ & $95.76 \pm 0.05$ & $95.28 \pm 0.04^{*}$ & 0.48 \\
Cylinder & & & \\
$1 \mathrm{~L} / \mathrm{min}$ & $99.90 \pm 0.07$ & $99.62 \pm 0.04 *$ & 0.28 \\
$3 \mathrm{~L} / \mathrm{min}$ & $99.98 \pm 0.04$ & $99.64 \pm 0.13^{*}$ & 0.34 \\
$5 \mathrm{~L} / \mathrm{min}$ & $99.92 \pm 0.08$ & $99.82 \pm 0.04$ & 0.10 \\
& & & \\
$* P<.05$ & & & \\
\hline
\end{tabular}

Furthermore, Cullen and Koss ${ }^{11}$ consider as clinically important flow reductions $\geq 20 \%$. Our results showed $<10 \%$ change in flow measurements, and are therefore considered not clinically important if we use the same criteria. ${ }^{11}$ It is important to point out that the ODS used in this study were verified by the manufacturer and considered adequate for the study.

To our knowledge, no other study has verified the $\mathrm{F}_{\mathrm{IO}_{2}}$ output in tubing length up to $98.42 \mathrm{ft}(30 \mathrm{~m})$. Despite the statistical difference observed between proximal and distal $\mathrm{F}_{\mathrm{IO}_{2}}$ measurements in all $3 \mathrm{ODS}$, the maximal difference between them was less than $1 \%$, which may not influence the clinical treatment. This is also an important finding, considering the historical belief that the length of the tubing may also affect the $\mathrm{F}_{\mathrm{IO}_{2}}$.

Finally, we chose to analyze $98.42-\mathrm{ft}$ (30-m) tubing, because this seems to be a length that could fit most of the patient's homes on LTOT with the studied ODS. This length should be enough to provide them with more freedom of movement within the home. In conclusion, tubing length at $98.42 \mathrm{ft}(30 \mathrm{~m})$ may be used by patients for home delivery oxygen with no important changes in flow or $\mathrm{F}_{\mathrm{IO}_{2}}$. Further studies, especially clinical ones, should be done to support these findings.

\section{REFERENCES}

1. Cazzola M, Donner CF, Hanania NA. One hundred years of chronic obstructive pulmonary disease (COPD). Respir Med 2007;101(6): 1049-65.

2. Cranston JM, Crockett AJ, Moss JR, Alpers JH. Domiciliary oxygen for chronic obstructive pulmonary disease. Cochrane Database Syst Rev 2005:CD001744.

3. Hanania NA AN, Calverley P, Cazzola P, Donner CF, Make B. Treatments for COPD. Respir Med 2005;99 (suppl B):S28-S40.

4. Nocturnal Oxygen Therapy Trial Group. Continuous or nocturnal oxygen therapy in hypoxemic chronic obstructive lung disease: a clinical trial. Ann Intern Med 1980;93(3):391-398.

5. Zieliński J. Effects of long-term oxygen therapy in patients with chronic obstructive pulmonary disease. Curr Opin Pulm Med 1999; $5(2): 81-87$.

6. Sant'Anna CA, Stelmach R, Zanetti Feltrin MI, Filho WJ, Chiba T, Cukier A. Evaluation of health-related quality of life in low-income patients with COPD receiving long-term oxygen therapy. Chest 2003; 123(1):136-141.

7. Diego González EG, Méndez Lanza A, Mosquera Pestaña JA. Noise and machine failures: determining factors in the acceptance and behavior of $\mathrm{O}_{2}$ concentrator. The Asturias project. An Med Interna 1996;13(9):430-433.

8. Shiner RJ, Zaretsky U, Mirali M, Benzaray S, Elad D. Evaluation of domiciliary long-term oxygen therapy with oxygen concentrators. Isr J Med Sci 1997;33(1):23-29.

9. Wedzicha JA. Effects of long-term oxygen therapy on neuropsychiatric function and quality of life. Respir Care 2000;45(1):119-124.

10. Global Initiative for Chronic Obstructive Pulmonary Disease - update 2014. http://www.goldcopd.org/uploads/users/files/GOLD_ Report2014_Feb07.pdf. Accessed March 29, 2014.

11. Cullen DL, Koss JA. Oxygen tubing lengths and output flows: implications for patient care. Chron Respir Dis 2005;2(4):193-197.

12. Davidson J, Gazzeta C, Torres LC, Jardim JR, Nascimento OA. Precision and accuracy of oxygen flow meters used at hospital settings. Respir Care 2012;57(7):1071-1075.

This article is approved for Continuing Respiratory Care Education credit. For information and to obtain your CRCE

(free to AARC members) visit www.rcjournal.com 